\title{
Evaluation of the Prognostic Value of BNP in Prediction of Sudden Cardiac Death in Patients with Left Ventricular Dysfunction after an Acute MI
}

\author{
AHMED YASSIN, M.Sc.; MOHAMED ABO HAMILA, M.D.; AHMED BATTAH, M.D.; AMAL RIZK, M.D. and \\ SHERIEF MOKHTAR, M.D.
}

The Department of Critical Care, Faculty of Medicine, Cairo University

\begin{abstract}
Background: Sudden Cardiac Death (SCD) is still a challenge despite advances in diagnostic and therapeutic and inspite of effectiveness of Implantable Cardioverter Defibrillators (ICDs), a better identification of patients with depressed ventricular function who could benefit from an ICD or, perhaps more importantly, those who are unlikely to benefit would helpin their management.
\end{abstract}

Aim of Study: Was To assess the prognostic value of Btype Natriuretic Peptide (BNP), in predicting sudden cardiac death within 90 days from the onset of MI in pts who developed $\mathrm{LV}$ dysfunction in this period.

Methods: We measured NT pro BNP in 60 consecutive post-STEMI patients with LV systolic dysfunction $(<\mathrm{EF} 50 \%)$, ( 45 men, represents $75 \%$ with mean age $57.6 \pm 8.4$ years old), 3 to 5 days after onset chest pain.

Results: Mean age of studied patients was $57.6 \pm 8.4$ years old (range $35-80$ ). Males constituted $73.3 \%$ of our study population (44 males), we found mean NYHA 2.8, mean Killip class of 2.9 and mean TIMI risk score of 8.3. Followup was done at 90 days. Forty eight patients survived (80\%), of whom life-threatening arrhythmias was documented in seven patients $(11.7 \%), 12$ pts had SCD (20\%). Pro-BNP as evidenced as a useful marker in predicting SCD by plotting the ROC curve that revealed AUC for 0.775 for prediction of sudden cardiac death, while AUC was $69.6 \%$ of ROC curve of same neuropeptide in evaluating accuracy in prediction VT, by. Kaplan Meier analysis shows that rise of pro-BNP above $3.2 \mathrm{ng} / \mathrm{ml}$ has a significant predictive impact upon SCD, [OR 0.748 (CI 95\%: 0.07-0.932), $p$-value .039].

Conclusion: BNP levels are a strong, independent predictor of sudden death in patients with ischemic cardiomyopathy after an acute MI.

Key Words: AUC: Area Uner the Curve - BNP: Beta Natruiretic Peptide - MI: Myocardial Infarction - SCD: Sudden Cardiac Death - VT: Ventricular Tachycardia - STEMI: ST Elevated Myocardial Infarction.

Correspondence to: Dr. Ahmed Yassin, The Department of Critical Care, Faculty of Medicine, Cairo University, Cairo, Egypt

\section{Introduction}

SUDDEN Cardiac Death (SCD) is still a challenge since it remains a major public health problem despite advances in diagnostic and therapeutic and inspite of effectiveness of Implantable Cardioverter Defibrillators (ICDs) [1-3] . To achieve the maximum benefit from ICD therapy, individual risk stratification is required in order to identify patients at increased risk for SCD and patients who would not get benefit and exposed to potential adverse effects [1-3]. Neuro hormones are secreted mainly in response to ventricular stretch in responce to volume and pressure overload [4] . Of those, Brain Natriuretic Peptide (BNP) and its precursor the amino terminal fragment of the BNP, pro hormone (NT-proBNP) are most studied.

In almost of all previous studies [4-8], that these peptides are powerful markers for prognosis, diagnosis, and risk stratification in Heart Failure (HF) patients.

Studies [9-12] have suggested that elevated plasma BNP or NT-pro BNP levels are associated with an increased risk of sudden cardiac death in patients with acute coronary syndromes.

In almost of these studies, it had been demonstrated that there was proportional and absolute increment above normal levels of the NT-proBNP exceeds that for BNP in left ventricular dysfunction, suggesting that NT-pro BNP may be a more sensitive prognostic marker compared to BNP [13]. Since a relationship between B-type natriuretic peptides and ventricular arrhythmia has been suggested [5,14-17].

Early after an acute myocardial infarction, BNP is released as a result of ischemia and necrosis of 
myo-cardial cells. Afterwards, BNP rises as a result of systolic or diastolic dysfunction and increased wall stress of the left ventricle [3-5]. Our study aimed to evaluate the importance of BNP levels in predicting the occurrence of malignant Ventricular Arrhythmias (VA) in patients with left ventricular dysfunction.

\section{Aim of the work:}

Assess the prognostic value of B-type Natriuretic Peptide (BNP), in predicting malignant ventricular arrhythmia that may lead to sudden cardiac death within 90 days from the onset of MI in pts developed LV dysfunction in this period.

\section{Patients and Methods}

The present study is a prospective observational study conducted on 60 consecutive patients who diagnosed to have acute STEMI complicated by LV systolic dysfunction \& admitted to Critical Care Department of Kasr El-Aini Hospital, Cairo University From 2015 to 2016.

Our patients included: 60 cases who was diagnosed to have STEMI, 46 pts under went primary intervention by PCI, while 14 pts received thrombolytic therapy.

\section{Inclusion criteria:}

- Adult patients diagnosed to have an acute myocardial infarction (STEMI), only if (at least 2 criteria of the following) were met:

1- Typical retro sternal chest pain (relieved by nitrates).

2- ST segment elevated greater than $0.1 \mathrm{mV}$ in limb leads or $0.2 \mathrm{mV}$ in precordial leads or new or indeterminate LBBB.

3- Elevated cardiac biomarker suggestive of myocardialinjury in early few hours.

-With echocardiographic evidence of LV systolic dysfunction (LVEF <50\%).

\section{Exclusion criteria:}

1- Renal impairment defined as serum creatinine level morethan $1.5 \mathrm{mg} / \mathrm{dl}$ that causes a non specific elevation of troponin.

2- Systemic sepsis that also causes a non specific elevation of troponin.

3- Cardiac arrest before taking samples.

4- Patients with cerebro vascular stroke.

5- Advanced malignancy.

\section{All patients were subjected to the following:}

1-Informed consent from the patient or the closest family member.

2- Detailed medical history taken from the patient or a family member.

3- Clinical assessment.

4- Surface 12 leads ECG.

5- Transthoracic echocardiographic examination.

6- Biochemical measurement

7- Coronary angiography.

Clinical assessment in the form of:

- Full physical examination.

- Clinical scoring systems: Used to evaluate patients with heart failure after an acute MI.

A- New York Heart Association: Functional classification based on severity of symptoms and physical activity.

- Class I: No limitation of physical activity. Ordinary physical activity does not cause undue breath lessness, fatigue or palpitaitons.

- Class II: Slight limitation of physical activity. Comfortable at rest, but ordinary physical activity results in undue breath lessness, fatigue, or palpitations.

- Class III: Marked limitation of physical activity. Comfortable at rest, but less than ordinary physical activity results in undue breath lessness, fatigue, or palpitations.

- Class IV: Unable to carry on any physical activity without discomfort. Symptoms at rest can be present. If any physical activity is undertake, discomfort is increase.

\section{Surface 12 leads ECG:}

Twelve lead ECG with consistent chest leads positioningperformed daily for 5 days.

ECG was considered abnormal if the following was detected:

- ST segment elevation greater than $0.1 \mathrm{mV}$ in limb leads or $0.2 \mathrm{mV}$ in precordial leads.

- Arrhythmias.

\section{Transthoracic echocardiographic examination:}

Each patient was examined in the left lateral position according to the recommendations of the American Society of Echocardiography (ASE). Images obtained from each part of the examination together with standard ECG were stored for 
subsequent analysis. The study was conducted using an ATL HDI 5000 colored echocardiographic machine, using a $3.5 \mathrm{MHz}$ transducer. 2D and $\mathrm{M}$ mode for assessment of:

- Left Ventricular Ejection Fraction (EF).

Biochemical measurement:

- Full laboratory investigation.

- Cardiac biomarkers (cardiac troponin I, CK MB, CPK, were measured on admission).

- Plasma samples withdrawn from every patient in our study in the first $48 \mathrm{hrs}$, to assess BNP.

\section{Coronary angiography:}

All patients were informed \& had a written consent.

The diagnostic angiograms were obtained using Digital Imaging and Communications in Medicine (DICOM)-compatible digital systems: Siemens AG model No.07555126 \& Philips CV20 with imaging speed: 15 frame per second (fps).

\section{Quantitative Coronary Analysis (QCA):}

The coronary parameters of major interest are summarized in Table (1):

Table (1): Main parameters obtained with QCA (adapted from Garrone et al., 2009)

\begin{tabular}{|c|c|}
\hline Range & Commonly used parameter range meaning \\
\hline $0-6.00 \mathrm{~mm}$ & - Minimal Luminal Diameter (MLD): \\
\hline $1.5-6.0 \mathrm{~mm}$ & $\begin{array}{l}\text { - The smallest lumen diameter in the segment } \\
\text { of interest. } \\
\text { - Reference Vessel Diameter (RVD) } \\
\text { - The averaged diameter of the coronary } \\
\text { assumed without atherosclerotic disease }\end{array}$ \\
\hline $0-60.0 \mathrm{~mm}$ & $\begin{array}{l}\text { - Lesion length: Length of the stenosis as } \\
\text { measured by } 2 \text { points where the coronary } \\
\text { margins change direction, creating a shoulder } \\
\text { between the angiographically normal } \\
\text { subsegment and the diseased subsegment. }\end{array}$ \\
\hline $0-100 \%$ & - Diameter Stenosis (DS): (RVD-MLD)/RVD \\
\hline
\end{tabular}

N.B.: The reference segment was defined as the segment leastaffected by atherosclerosis within a $10 \mathrm{~mm}$ span proximal and distal to the target lesion.

- Follow-up was done for all survived pts in our group studied and also those were rescusitated from SCD, by full clincal examination, history taking of palpitation,syncopal attacks and also 12 leads ECG to assess occurrence of ventricular arrhythmia in these pts, within 90 days period from onset of MI.

\section{Results}

Our study is prospective observational study conducted on 60 adult patients admitted to Critical Care Department (Cairo University) as having acute MI and post MI L.V systolic dysfunction throughout the period from September 2014 to March 2015.

\section{A- Demographic and descriptive data:}

Our study was conducted on sixty patients with LV dysfunction, complicating the course of acute MI. Mean age of studied patients was $57.6 \pm 8.4$ years old (range 35-80). Males constituted $73.3 \%$ of our study population (44 males and 16 females).

Forty six pts were subjected to primary percutaneous coronary intervention $(76.7 \%)$ while fourteen pts received medical treatment $(23.3 \%)$.

\section{Clinical examination:}

Risk category stratification in our patients, showed mean NYHA 2.8, Killip class of 2.9 and TIMI risk score of 8.3. as shown in Table (2):

Table (2): Clinical Examination in NYHA, Killip Class.

\begin{tabular}{ll}
\hline \multicolumn{2}{c}{ Clinical examination } \\
\hline NYHA & $2.8 \pm 0.8$ \\
KILLIP class & $2.8 \pm 0.8$ \\
TIMI risk point & $7.8 \pm 2.4$ \\
\hline
\end{tabular}

\section{Follow-up clinical examination:}

Follow-up clinical examination was done for survivors and showed a mean NYHA: $1.9 \pm 0.7$.

Follow-up was done at 90 days. Forty eight patients survived $(80 \%)$ from those seven patients documented in life-threatening arrhythmias (11.7\%) and sudden cardiac deathwere developed in 12 pts in our population.

\section{Initial echocardiographic examination:}

Echocardiographic examination was done for all patients and showed a mean EF of $41.9 \pm 8 \%$ with RWMA: $13.3 \pm 3.3$ as shown in Table (3).

Table (3): Initial Echocardiographic examination.

\begin{tabular}{lc}
\hline \multicolumn{3}{l}{ Echocardiographic examination } \\
\hline LVEF & $41.9 \pm 8 \%$ \\
RWMA & $13.3 \pm 3.3$ \\
\hline
\end{tabular}

Twenty seven patients had initial EF value higher than or equal to $45 \%$, while 20 patients had $\mathrm{EF}$ values ranging between 35 and $45 \%$ and only 13 patients had values lower than $35 \%$. 


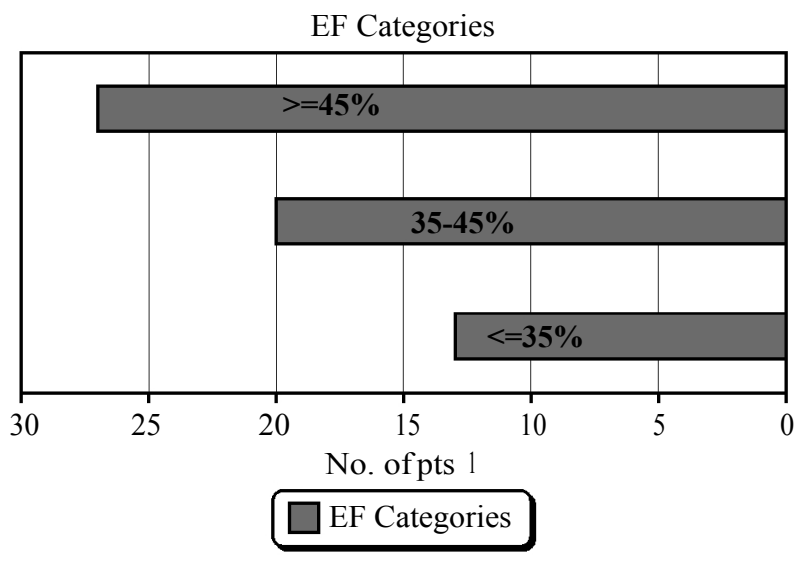

Fig. (1): EF Categories.

Follow-up echocardiographic examination:

Follow-up echocardiographic examination was done for survivors and showed a mean EF of $46.7 \pm 8.8 \%$ with RWMA: $8.7 \pm 4.1$ as shown in Table (4):

Table (4): Follow-up echocardiographic examination for survivors patients.

\begin{tabular}{ll}
\hline \multicolumn{2}{c}{ ECHO examination } \\
\hline EF & $46.7 \pm 8.8 \%$ \\
RWMW & $8.7 \pm 4.1$ \\
\hline
\end{tabular}

Table (5): Cut off points of Pro-BNP for prediction of ventricular arrhythmia $(\mathrm{No}=7)$.

\begin{tabular}{lccccc}
\hline V.tach/VF & AUC & $\begin{array}{c}p- \\
\text { value }\end{array}$ & $\begin{array}{r}\text { Cut- } \\
\text { off }\end{array}$ & Sensitivity & Specificity \\
\hline $\begin{array}{c}\text { Pro-BNP } \\
(\mathrm{ng} / \mathrm{ml})\end{array}$ & $69.6 \%$ & .017 & 3.13 & $72.2 \%$ & $61.9 \%$ \\
\hline
\end{tabular}

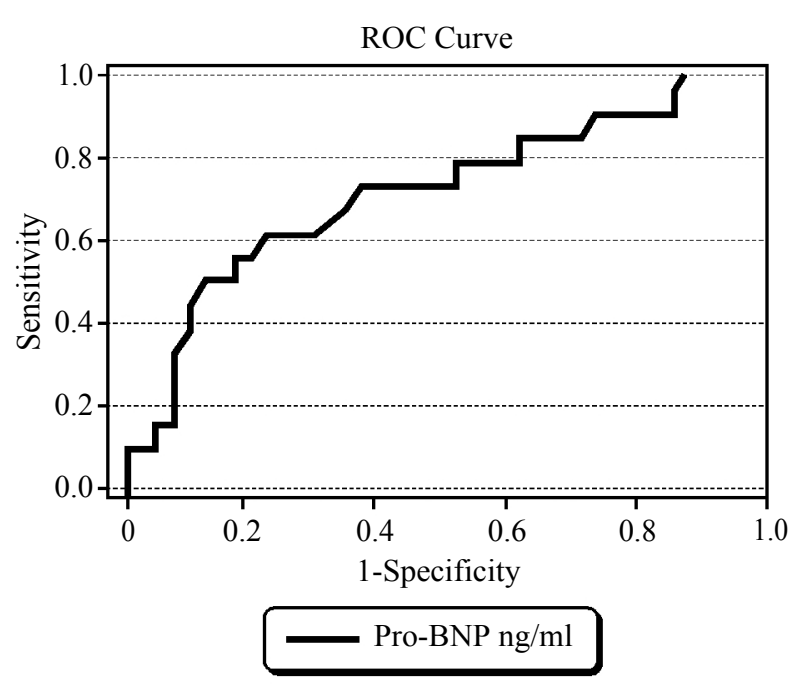

Fig. (2): ROC analysis for Sudden cardiac death.

Plotting ROC curve to estimate the best predictive cutoff points as predictors of sudden cardiac death pro-BNP revealed the following:
Table (6): Cut off points of Pro BNP in group developed Sudden cardiac death $(\mathrm{No}=12)$.

\begin{tabular}{lccccc}
\hline SCD & AUC & $\begin{array}{c}p- \\
\text { value }\end{array}$ & $\begin{array}{c}\text { Cut- } \\
\text { off }\end{array}$ & Sensitivity & Specificity \\
\hline $\begin{array}{l}\text { Pro-BNP } \\
(\mathrm{ng} / \mathrm{ml})\end{array}$ & $77.5 \%$ & $<0.001$ & 3.2 & $70 \%$ & $67.5 \%$ \\
\hline
\end{tabular}

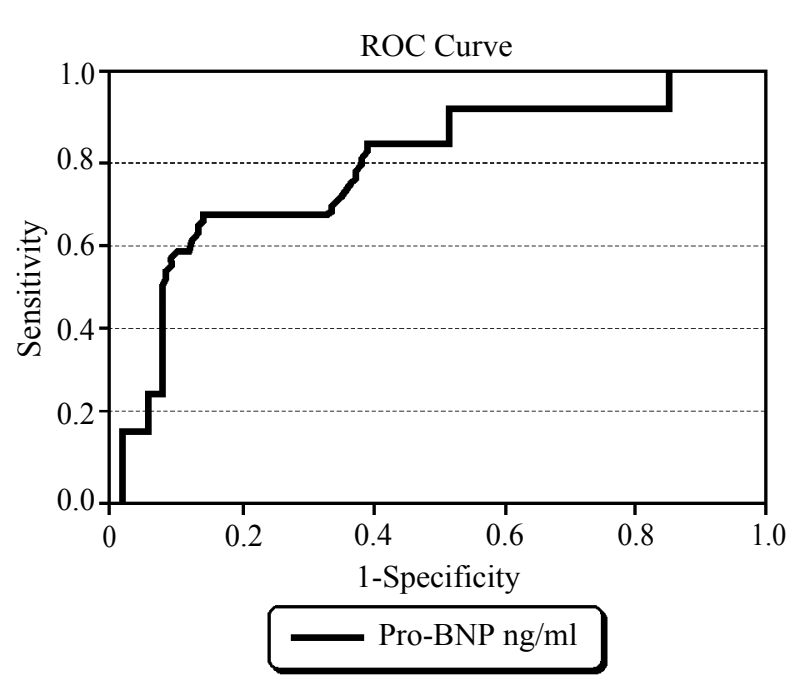

Fig. (3): Cut off points of Pro BNP for specificity and sensitivity.

B- Examining the prognostic accuracy of pro-BNP using survival analysis:

Kaplan Meier analysis shows that rise of proBNP above $3.2 \mathrm{ng} / \mathrm{ml}$ has a significant predictive impact upon SCD, [OR 0.748 (CI 95\%: 0.07$0.932), p$-value .039].

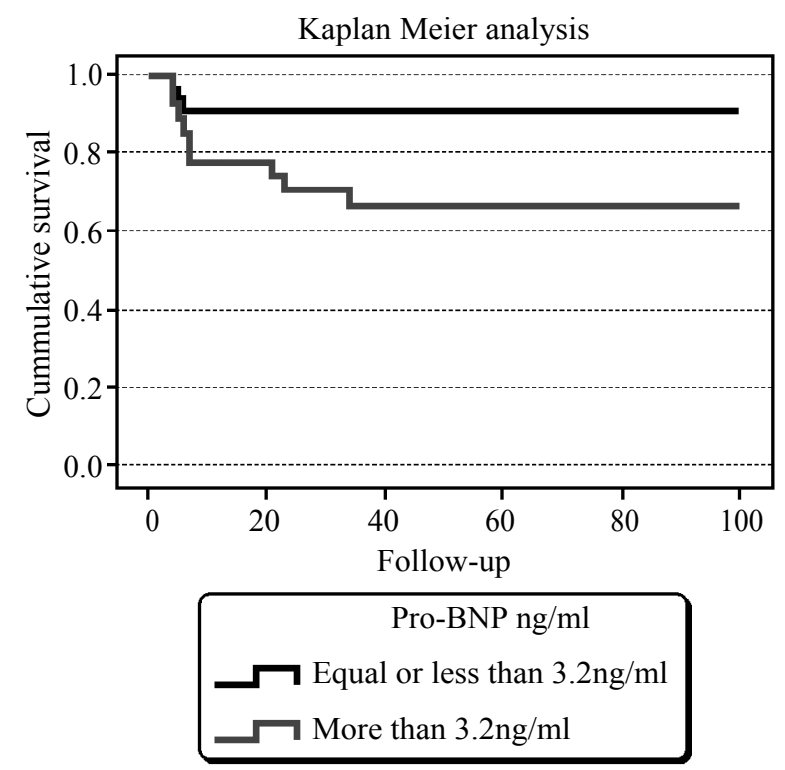

Fig. (4): Kaplan Meier analysis for Pro BNP.

\section{Discussion}

AMI is a major mortality cause and in spite of recentdiagnostic and therapeutic improvements; 
mortality and morbidity rate of this condition is already remained high. Recently, B-type Natriuretic Peptide (BNP) has been recognized as a useful marker for predicting acute and chronic left ventricular dysfunction. Patients with acute ST Elevation Myocardial Infarction (STEMI) who had higher levels of BNP have been shown to have worse prognosis [8-12]. ICDs are the treatment of choice for patients who are at high risk for potentially fatal ventricular arrhythmias [1-3]. It has been increasingly recognized that ICDs are superior to anti arrhythmic drugs in survivors of cardiac arrest or unstable VT [19-21]. And that they are more beneficial than drug therapy for primary prevention of SCD in certain high-risk groups [22-25]. This is particularly true for patients with severe ischemic cardiomyopathy, the population of our study. Thus, a better identification of patients with depressed ventricular function who could benefit from an ICD or, perhaps more importantly, those who are unlikely to benefit would help in their management.

Our study aimed to evaluate the role BNP for better prediction of the high risk pts for SCD, to improve risk stratification in these group of pts.

In addition to all previous reports about usefulness of such marker as prognostic marker for pts developed acute heart failure, we found BNP is also, a useful marker in predicting SCD, in post STEMI pts, with LV systolic dysfunction with (ROC curve $77.5 \%, p$-value 0.001 , sensitivity $70 \%$, specifity $67.5 \%)$.

In similar to our findings, Yang et al., studied on 246 AMI patients with 14 months follow-up and investigated several indexes, as like as BNP to determine the most valuable prognostic factors for AMI induced mortality, They found, with multiple regression analysis, that BNP is an independent risk factor and an appropriate prognostic index for mortality rate estimation, in short and long term after AMI [14]. Although, there are few evidences about BNP levels and major electrical complications.

As a regard usefullness of BNP in prediction of ventricular arrhythmia, Blangy et al., reported that, together with serving as a marker of left ventricular dysfunction, BNP level is marker of Ventricular Tachyarrythmia (VT) as well, and increased serum BNP was associated with a higher incidence of VT.

Also,our study reported promising role of BNP ,in predicting V.tach, in pt with ischemic cardiomyopathy after acute STEMI, (with ROC curve
$69.9 \%, p$-value 0.017 , sensitivity $72.2 \%$, specifity $61.9 \%$.

Several studies have shown that altered systemic or cardiac autonomic nervous function is related to the triggering or exacerbation of heart failure and the ventricular arrhythmias responsible for lethal cardiac events. Autonomic nervous function has both favorable (compensatory) and unfavorable effects on cardiovascular diseases and outcomes [22-25].

Although cardiac autonomic function has been shown to be an independent powerful prognostic marker, arrhythmo genesis, lethal cardiac events, and long-term prognosis are multifactorial and haveseveral known determinants: Left Ventricular Ejection Fraction (LVEF), a history of ischemia, the size of the ischemic burden, coronary risk factors, electrophysiologic indices, and the plasma concentration of Brain Natriuretic Peptide (BNP). In other words, there is no single powerful predictor of arrhythmic death and effectiveness of prophylactic ICDuse. Emmanuel G. et al., stated that To achieve the maximum benefit by ICD therapy, more precise risk stratification is required, even in high-risk, post-myocardial infarction patients.

\section{Conclusion:}

BNP levels are a strong, independent predictor of sudden death in patients with ischemic cardiomyopathy after an acute MI.

\section{References}

1- RAY I.B. and REDDY V.Y.: Implanted defibrillators and primary prevention of sudden cardiac death: Where are we today? Int. J. Cardiol., 98: 15-20, 2005.

2- JOSEPHSON M. and WELLENS H.J.: Implantable defibrillators andsudden cardiac death. Circulation, 109: 268591, 2004.

3- HUIKURI H.V., MAKIKALLIO T.H., RAATIKAINEN M.J., et al.: Predictionof sudden cardiac death: Appraisal of the studies and methodsassessing the risk of sudden arrhythmic death. Circulation, 108: 110-5, 2003.

4- MAISEL A.S.: B-type natriuretic peptide (BNP) levels: diagnostic and therapeutic potential. Rev. Cardiovasc. Med., 2 (Suppl 2): S13-S18, 2001.

5- BERGER R., HUELSMAN M., STRECKER K., et al.: B-type natriureticpeptide predicts sudden death in patients with chronic heartfailure. Circulation, 105: 2392-7, 2002.

6- GARDNERA R.S., OZÄLP F., MURDAYA A.J., et al.: $\mathrm{N}$-terminal pro-brain natriuretic peptide: A new gold standard in predictingmortality in patients with advanced heart failure. Eur. Heart J., 24: 1735-1743, 2003.

7- KOGLIN J., PEHLIVANLI S., SCHWAIBLAMIR M., et al.: Role of brainnatriuretic peptide in risk stratification of patients withcongestive heart failure. J. Am. Coll. Cardiol., 38: 1934-41, 2001. 
8- HARRISON A., MORRISON L.K., KRISHNASWAMY P., et al.: B-type Natriuretic Peptide (BNP) predicts future cardiac events inpatients presenting to the emergency department with dysnea. Ann. Emerg. Med., 39: 131-8, 2002.

9- TAPANAINEN J.M., LINDGREN K.S., MAKIKALLIO T.H., et al.: Natri-uretic peptides as predictors of nonsudden and suddencardiac death after acute myocardial infarction in the-blocking era. J. Am. Coll. Cardiol., 43: 757-63, 2004.

10- HEESCHEN C., HAMM C.W., MITROVIC V., et al.: Nterminalpro-B-type natriuretic peptide levels for dynamic risk strati-fication of patients with acute coronary syndromes. Circulation, 110: 3206-12, 2004.

11- OMLAND T., PERSSON A., NG L., et al.: N-terminal pro-B- typenatriuretic peptide and long-term mortality in acute coronarysyndromes. Circulation, 106: 2913-8, 2002.

12- GALVANI M., OTTANI F., OLTRONA L., et al.: Nterminal pro-brainnatriuretic peptide on admission has prognostic value acrossthe whole spectrum of acute coronary syndromes. Circulation, 110: 128-34, 2004.

13- HUNT P.J., RICHARDS A.M., NICHOLLS M.G., et al.: Immunoreactiveamino-terminal pro-brain natriuretic peptide (NT-PROBNP): A new marker of cardiac impairment. Clin. Endo-Crinol., 47: 287-96, 1997.

14- HANSEN D.E., CRAIG C.S. and HNDEGHEM L.M. Stretch-induced arrhythmias in the isolated canine ventricle: Evidence for the importance of mechanoelectrical feedback. Circulation, 81: 1094-105, 1990.

15- FRANZ M.R., CIMA R. and WANG D.: Electrophysiological effects of myocardial stretch and mechanical determinants for stretch-activated arrhythmias. Circulation, 86: 968-78, 1992.

16- REITER M.J.: Effects of mechanoelectrical feedback: Influence among patients with congestive heart failure. Cardiovasc. Res., 32: 44-51, 1996.

17-ZHU W.X., JOHNSON S.B., BRANDT R., et al.: Impact of volume loading and load reduction on ventricular refractoriness and conduction properties in canine congestive heart failure. J. Am. Coll. Cardiol., 30: 825-33, 1997.
18- MUKOYAMA M., NAKAO K., HOSODA K., et al. Brain natriuretic peptide as a novel cardiac hormone in humans. Evidence for an exquisite dual natriuretic peptide system, atrial natriuretic peptide and brain natriuretic peptide. J. Clin. Invest, 87: 1402-12, 1991.

19- YOSHIMURA M., YASUE H., OKUMURA K., et al.: Different secretion patterns of atrial natriuretic peptide and brain natriuretic peptide in patients with congestive heart failure. Circulation, 87 (2): 464-69, 1993.

20- MAEDA K., TSUTAMOTO T., WADA A., et al.: Plasma brain natriuretic peptide as a biochemical marker of high left ventricular end-diastolic pressure in patients with symptomatic left ventricular dysfunction. Am. Heart J., 135: 825-32, 1998.

21- MAISEL A.S., KRISHNASWAMY P., NOWAK R.M., et al.: Rapid measurement of B-type natriuretic peptide in the emergency diagnosis of heart failure. N. Engl. J. Med., 347: 161-7, 2002.

22- MORRISON L.K., HARRISON A., KRISHNASWAMY $P$., et al.: Utility of a rapid B-natriuretic peptide assay in differentiating congestive heart failure from lung disease in patients presenting with dyspnea. J. Am. Coll. Cardiol., 39: 202-9, 2002.

23- YANG Y.J., MAO Y., NI X.H., et al.: The predictive value of B-type natriuretic peptide for the mortality from acute myocardial infarction. ZhonghuaNeiKeZaZhi, 46: 4503, 2007.

24- BLANGY H., SADOUL N., DOUSSET B., et al.: Serum $\mathrm{BNP}$, hs-C-reactive protein, procollagen to assess the risk of ventricular tachycardia in ICD recipients after myocardial infarction. Europace., 9: 724-9, 2007.

25- FAZLINEZHAD, M. KHADEM REZAEIAN ${ }^{2}$, H. YOUSEFZADEH, et al.: Clinical Medicine Insights: Cardiology, 577-83, 2011.

26- EMMANUEL G. MANIOS, M.D. and ELEFTHERIOS M.: Chest, 128: 2604-10, 2005.

27- GARRONE P., BIONDI-ZOCCAI G. and SALVETTI, I. Quantitative coronary angiography in the current era: Principles and applications. J. Interv. Cardiol., 22: $527-$ 36, 2009. 


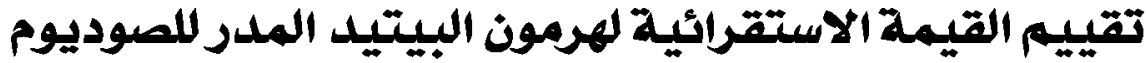

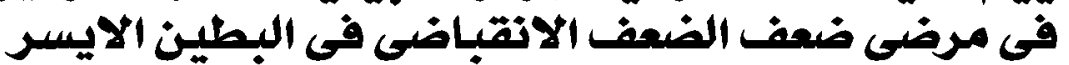

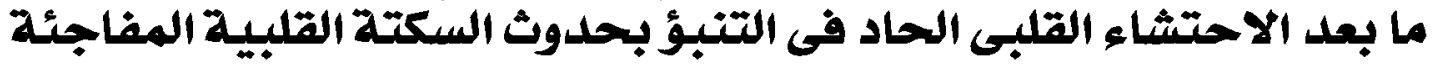

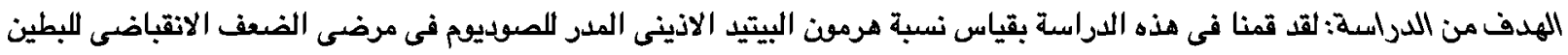

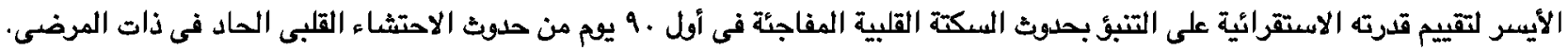
طريقة عمل الدراسة: لقد قمنا في هذه الدراسة بقياس نسبة هرمون البيتيد الاذينى المدر الصبوديوم فى مرضى الضعف الإنى الانقباضى اللبطين

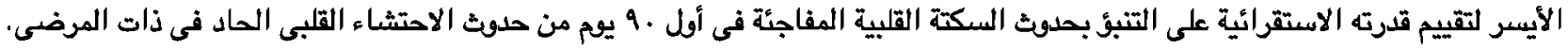

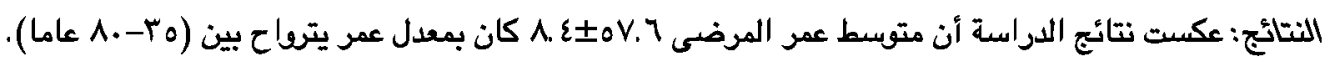

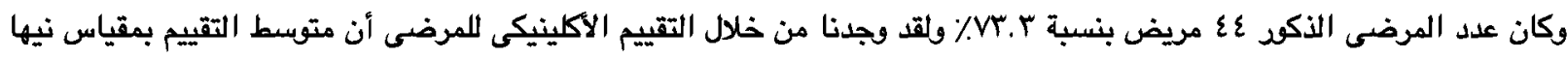

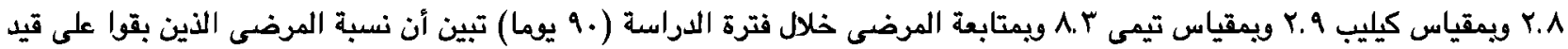

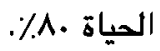

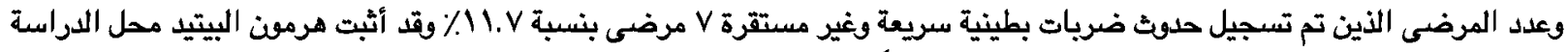

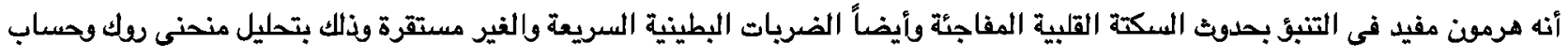
المساحة تصت المنحنى.

وكانت النتيجة بالنسبة للتقييم بالتنبؤ بحدوث السكتة القلبية المفاجئة ه. هV بينما كانت بالنسبة للتنبؤ بحدوث الضريات البطينية السريعة

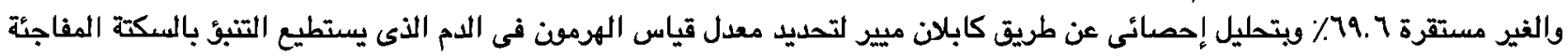

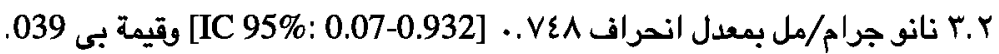

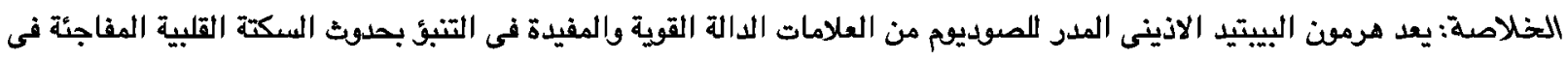
مرضى الضعف الانقباضى اللبطين الأيسر ما بعد الإيني الاحتشاء القلبى الحاد. 